\title{
Original article \\ Impact of acute static-stretching on the optimal height in drop jumps
}

\author{
Leonardo A. Pasqua \\ Nilo M. Okuno \\ Mayara V. Damasceno \\ University of São Paulo, Brazil \\ Adriano. E. Lima-Silva \\ Federal University of Pernambuco, Brazil \\ Rômulo Bertuzzi \\ University of São Paulo, Brazil
}

\begin{abstract}
This study analyzed the effect of static stretching on performance during drop jumps. Furthermore, we investigated if a reduction in drop height would compensate the stretching-caused alterations. Ten physically active male subjects performed drop jumps at four different drop heights without static stretching for the optimal drop height determination. After, they performed drop jumps on two drop heights with static stretching previously. The jump height, contact time and reactive strength index were significantly affected by static stretching. However, only the contact time was significantly improved by the reduction in drop height with previous static stretching. Our results suggest that the decrement in performance after static stretching could be partially compensated by a reduction in drop height, which decreases the contact time near a non-stretching jump condition. This can be explained by the lower landing velocity and, possibly, the smaller reduction in the activation of the plantar flexors muscles. In conclusion, the reduction in drop height seems to be interesting after a static stretching session, aiming to expose the athletes to lower impact forces to maintain jump performance.
\end{abstract}

Keywords: muscle power, jump performance, drop height, stretching

Resumo - “Impacto agudo do alongamento estático sobre a altura ideal de queda no salto em profundidade." O presente estudo analisou o efeito do alongamento estático sobre o desempenho no salto em profundidade. Adicionalmente, foi investigada a redução na altura de queda poderia compensar as alterações causadas pelo alongamento prévio. Dez homens fisicamente ativos realizaram o salto em profundidade em quatro alturas de queda diferentes sem alongamento estático prévio, para determinação da altura de queda ideal, em duas alturas com o alongamento prévio. A altura de salto, o tempo de contato e o índice de força reativa foram significativamente afetados pelo alongamento estático. Contudo, apenas o tempo de contato foi significativamente melhorado com a redução na altura de queda do salto após o alongamento. Nossos resultados sugerem que a diminuição no desempenho após o alongamento pode ser parcialmente compensada com uma redução na altura de queda, diminuindo o tempo de contato para valores próximos ao salto sem alongamento prévio. Isso pode ser explicado pelo menor velocidade de aterrissagem e, possivelmente, pela menor redução na ativação dos músculos flexores plantares. Assim, a diminuição na altura de queda parece ser interessante após a realização do alongamento estático, visando submeter os atletas a menores forças de impacto e manter o desempenho do salto.

Palavras-chave: potência muscular; desempenho de salto; altura de queda; alongamento

Resumen - "Impacto agudo del estiramiento estático sobre la altura óptima de caída en el salto en profundidad." En este estudio se analizó el efecto del estiramiento estático sobre el rendimiento en saltos en profundidad. Además, se investigó si una reducción de la altura de caída compensaría las alteraciones causadas por el estiramiento previo. Diez hombres físicamente activos realizaron el salto en profundidad en cuatro alturas diferentes de caída sin estiramiento estático, para la determinación de la altura de caída óptima y en dos alturas con el estiramiento estático previo. La altura del salto, el tiempo de contacto y el índice de fuerza reactiva fueron afectados significativamente por el estiramiento estático. Sin embargo, sólo el tiempo de contacto mejoró significativamente por la reducción de la altura de caída del salto, después del estiramiento. Nuestros resultados sugieren quela disminución en el rendimiento después del estiramiento estático, podría ser parcialmente compensada con una reducción en la altura de caída, disminuyendo el tiempo de contacto para 
valores próximos al del salto sin estiramiento previo. Esto se puede explicar por la menor velocidad de aterrizaje y, posiblemente, por la menor reducción en la activación de los músculos flexores plantares. En conclusión, la reducción de la altura de caída parece ser interesante después de realizar una sesión de estiramientos estáticos, con el objetivo de someter a los atletas a menores fuerzas de impacto y mantener el rendimiento en el salto.

Palabras clave: fuerza muscular; rendimiento del salto; altura de caída; estiramiento

\section{Introduction}

Plyometric training is considered to be an effective method to increase muscle power of the lower limbs (Miller, Herniman, Ricard, Cheatham, \& Michael, 2006; Thomas, French, \& Hayes 2009). Drop jump is characterized by a stretch-shortening cycle, in which an eccentric contraction is followed by a concentric contraction (Spurrs, Murphy, \& Watsford, 2003). The stretch -shortening cycle seems to increase power generation when performed quickly in the concentric action partly due to a return of the elastic energy stored by the passive structures of the muscle-tendon unit during the eccentric contraction (Malisoux, Francaux, Nielens, \& Theisen 2006).

Although there are several exercises involving stretch-shortening cycle, such as the countermovement jump (Bradley, Olsen, \& Portas 2007) and the hurdle jump (Vissing et al., 2008), previous studies have suggested that the plyometric exercises, as the drop jump is one of the most important exercises to optimize the stretch-shortening cycle (Byrne, Moran, Rankin, \& Kinsella 2010; Kyröläinen et al., 2004; Markovic, 2007). An important aspect that has been considered for prescription of the drop jump training is the initial drop height. For example, Laffaye, Bardy, and Taiar (2006) observed that jump performance was higher when a $60-\mathrm{cm}$ initial drop height was used compared with a $30-\mathrm{cm}$ initial drop height. In addition, Ball, Stock, and Scurr (2010) conducted a study analyzing drops from 20,40 and $60 \mathrm{~cm}$ and found that the increase in drop height enhances the vertical ground reaction force, impulse and contact time. Thus, it is important to identify an optimal drop height, which has been largely identified as the drop height that provides either the highest jump height or the shortest contact time during the propulsive phase (Byrne et al., 2010). Moreover, the optimal drop height could also be determined by a reactive strength index, which is defined as the jump height divided by the contact time (Young \& Elliot, 2001).

It is interesting to note that factors other than drop height alone can also affect drop jump training. For example, static stretching (SS) seems to negatively affect the performance on drop jump (Behm \& Kibele, 2007), possibly by an alteration in the muscle length-tension relationship, which changes the ability of the muscle-tendon unit to store elastic energy (Cramer et al., 2004). Indeed, Fletcher and Monte-Colombo (2010) showed that a static stretching bout decreases the drop jump performance $(45.2 \pm 3.7 \mathrm{~cm})$ compared to both dynamic stretching $(48.0 \pm 4.9 \mathrm{~cm})$ and nonstretching warm-up $(47.5 \pm 5.6$ $\mathrm{cm})$. Additionally, a lower reactive strength index was obtained in drop jump after SS condition compared to proprioceptive neuromuscular facilitation and nonstretching conditions, as showed by Young and Elliot (2001). Then, it is reasonable to expect that SS, due a decrement in the power generation ability, would reduce jump height and increase contact time and, consequently, change the optimal drop height.

From a practical standpoint, in despite of several athletes and coaches have been included dynamic stretching exercises as part of their warm-up routines, based on recent findings regarding acute detrimental effects of SS on force and power production (Fletcher \& Monte-Colombo, 2010), in some modalities that require static stances in stretched positions the SS is an essential portion of a training session. Thus, athletes of modalities that require high levels of both muscle power and flexibility (e.g., gymnastics) may be interested in results indicating whether they should train with a lower drop height after SS to optimize jump performance. However, to our knowledge, the impact of SS on the optimal drop height remains unknown.

Therefore, to the best of our knowledge, no studies have investigated the impact of SS, which is a key exercise in some modalities, on the optimal drop height on drop jumps, an important factor to be considered in training prescription. Thus, the aim of the present study was to analyze whether the performance on drop jump is acutely diminished by SS and whether a decrease in the drop height would compensate this deleterious effect. We hypothesized that acute SS would decrease the jump height and increase the contact time. Consequently, a reduction in the drop height will compensate the $\mathrm{SS}$ effects, leading to a better performance after a reduction in the optimal drop height.

\section{Methods}

\section{Participants}

Ten physically active male volunteers (age $24.3 \pm 4.7$ years; height $178.1 \pm 5.6 \mathrm{~cm}$; weight $74.4 \pm 7.2 \mathrm{~kg}$ ) participated in this study. They were engaged in regular physical activities for a minimum of 1 year prior to the study, and they were free of any lower extremity injuries. Their activities include resistance exercises and running up to 3 times a week, but none of the volunteers were familiar with the drop jump. All participants received verbal explanation about the possible benefits and risks associated with the study and signed an informed consent form before participation. This investigation was approved by the School of Physical Education and Sports Ethics Committee for Human Studies from the University of São Paulo. 


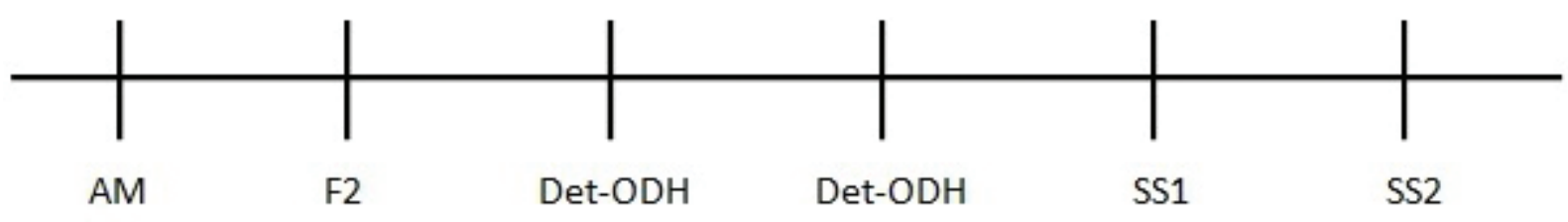

F1

Figure 1. Familiarizations and experimental sessions. AM: Anthropometric measures; F1: Familiarization with two drop heights; F2: Familiarization with two other drop heights; Det-ODH: Determination of the optimal drop height; SS1: Static stretching + drop jump at the optimal drop height; SS2: Static stretching + drop jump at the height $20 \mathrm{~cm}$ below the optimal drop height.

\section{Experimental approach to the problem}

Previous findings suggested that performance in drop jumps is indicative of muscle power and that SS acutely decreases performance in this form of exercise. Thus, we were interested in analyzing if the acute SS would reduce the performance on optimal drop height and if a reduction on drop height will compensate the SS effects. To reach this goal, all of the participants visited the laboratory on six different days (figure 1). They performed the following tests: 1) anthropometric measures and familiarization at two different drop heights; 2) familiarization in two other drop heights; 3 and 4) performance evaluation on the four drop heights for the determination of the optimal drop height without previous SS (CON); 5) drop jump at optimal drop height preceded by SS (SS1) to verify the effects of SS on performance and; 6) drop jump at drop height $20 \mathrm{~cm}$ below the optimal drop height preceded by SS (SS2) to verify if a lower starting height could correct any deleterious effect of the SS. The drop heights in the familiarization (sessions 1-2) and tests (sessions 3-4 and 5-6) were performed in a counterbalanced manner. They were conducted at the same time of day with intervals of at least 48 hours between the sessions. The participants were instructed to refrain from exhaustive exercise for 24 hours preceding testing sessions and to maintain the same dietary habits throughout the study.

\section{Familiarization and optimal drop height determination}

Before each familiarization and optimal drop height determination sessions, the participants warmed up for 5 minutes at $70 \mathrm{~W}$ on a cycle ergometer. Thereafter, 3 jumps at each drop height were performed with a 30 -seconds rest interval between the jumps and a 2-minutes rest interval between the two different heights (Fletcher \& Monte-Colombo, 2010). The drop heights used were 20, 40, 60 and $80 \mathrm{~cm}$, but only two drop heights were tested per session. The order of the drop heights was randomly defined. The participants were instructed to jump as fast and as high as they could (Young \& Elliot, 2001) and to perform all jumps with their hands on the hips. The jumping tests were conducted on a contact mat (MultiSprint, Hidrofit, Brazil) to measure the contact time and the flight time, which were used to estimate the jump height. The best reactive strength index among the three jumps for a particular height was considered to determine the optimal drop height (equation 1). This variable was chosen because it was a good way to evaluate the ability to develop maximal force into a minimal time interval, which is an important characteristic in most sports (Zatsiorsky \& Kraemer, 2007).

$$
\mathrm{RSI}=\mathrm{JH} / \mathrm{CT}
$$

Equation 1. Equation of the reactive strength index used in the optimal drop height determination. RSI: reactive strength index; JH: jump height; CT: contact time

\section{Flexibility and static stretching bout}

The SS routines comprised six different exercises for the lower leg, which have been reported elsewhere (Samogin Lopes, Menegon, Franchini, Tricoli, \& Bertuzzi, 2010). Briefly, the exercises consisted of: 1) Unassisted straight-leg stand and toe touch; 2) assisted thigh stretching; 3 ) unassisted standing quadriceps stretching; 4) unassisted hamstrings and back stretching; 5) unassisted hurdler's stretching and; 6) assisted quadriceps and hip stretching. Each exercise was performed three times, and the stretching position was maintained for 30 seconds. A 30 -seconds rest interval was taken between sets. The intensity was set at a point where the individual verbally reported mild discomfort, which was established as a score of 7 on Borg CR10 scale (Borg, 1998). The total duration of a SS session was approximately 30 minutes. It has been demonstrated that this stretching protocol causes significant decreases in muscle strength, but is effective to improve lower limbs flexibility (Behm \& Kibele, 2007).

The flexibility sit-and-reach test was applied before and immediately after SS to assess the efficacy of SS to improve flexibility of the lower limbs (Baltaci, Um, Tunay, Besler, \& Gerçeker, 2003). The participants sat with their bare feet pressed against the sit-and -reach box with their knees extended and their right hand positioned over the left. They were asked to push a ruler transversally located over the box as far as possible. Three trials were performed and the best score was used for statistical analyses.

\section{Drop jump after static stretching}

After each SS routine, three drop jumps were performed as soon as possible ( $\sim 60$ seconds after SS). The jump tests were conducted in the same manner as were the nonstretching sessions. The best reactive strength index was used for statistical analyses. 


\section{Statistical analyses}

Data normality was assessed through the Shapiro-Wilk test, and all of the variables showed normal distributions. The results were reported as the means $\pm \mathrm{SD}$. The paired Student $t$-tests were used to determine the difference in flexibility before and after SS protocol in the conditions SS1 and SS2. The differences in jump height, contact time and reactive strength index between the 3 conditions (CON, SS1 and SS2) were compared through ANOVA for repeated measures. When were observed significant difference, a Tukey's post-hoc test was used. Sphericity of the data was analyzed by Mauchly's test. The magnitude of the difference among experimental conditions was expressed as effect size and classified as trivial $(<0.35)$, small $(0.35-0.80)$, moderate (0.81-1.50) or large (>1.5) (Rhea, 2004). All statistical analyses were conducted using SPSS version 16.0 for Windows (SPSS Inc., Chicago, IL, USA), and significance was set at $p \leq 0.05$.

\section{Results}

The optimal drop height was found at $60.0 \pm 18.9 \mathrm{~cm}$. The jump height, contact time and reactive strength index at the optimal drop height were $38.0 \pm 5.0 \mathrm{~cm}, 0.386 \pm 0.130 \mathrm{~s}$ and $109.99 \pm 44.04 \mathrm{~cm} . \mathrm{s}^{-1}$, respectively.

As expected, the SS routine effectively improved lower limb flexibility in both SS1 $(30.4 \pm 10.5$ vs. $34.2 \pm 9.5 \mathrm{~cm})$ and SS2 $(29.5 \pm 10.0$ vs. $33.5 \pm 9.6 \mathrm{~cm}$ before and after stretching, respectively, $p<0.05$ ), but there were no differences in the flexibility improvements between the sessions.

Figure 2 shows the comparison of the jump height, contact time and reactive strength index among CON, SS1 and SS2. Jump height (Figure 2a) and reactive strength index (Figure 2c) were significantly higher in CON than in both SS1 and SS2, but there were no differences between SS1 and SS2. However, contact time (Figure 2b) was increased in SS1 compared with $\mathrm{CON}$, but there were no differences between CON and SS2 or between SS1 and SS2.

The effect size values are shown in Table 1. The effect sizes between CON and SS1 and between CON and SS2 were classified as small for jump height and trivial for both contact time and reactive strength index. Additionally, the effect size values between SS1 and SS2 were classified as trivial for the three parameters.

\section{Discussion}

The present study was designed to analyze whether performance-related parameters of drop jump (jump height, contact time and reactive strength index) are acutely diminished by SS and whether these parameters are enhanced after a decrease in the drop height. As expected, jump height, contact time and reactive strength index were negatively influenced by SS. However, the main finding of the present study was that only the contact time returned to a value similar to the CON after a reduction in the drop height after the participants performed an identical SS protocol. a
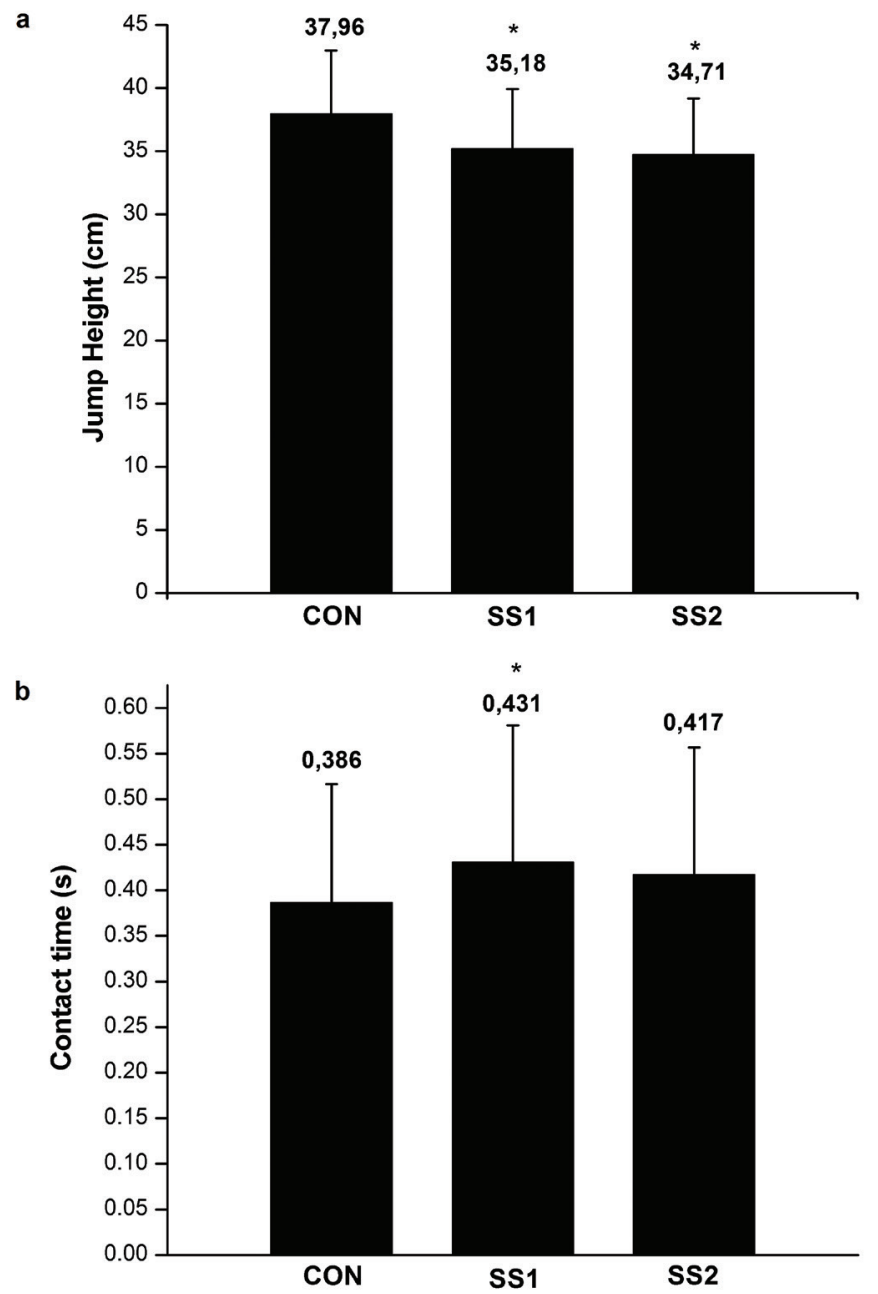

c

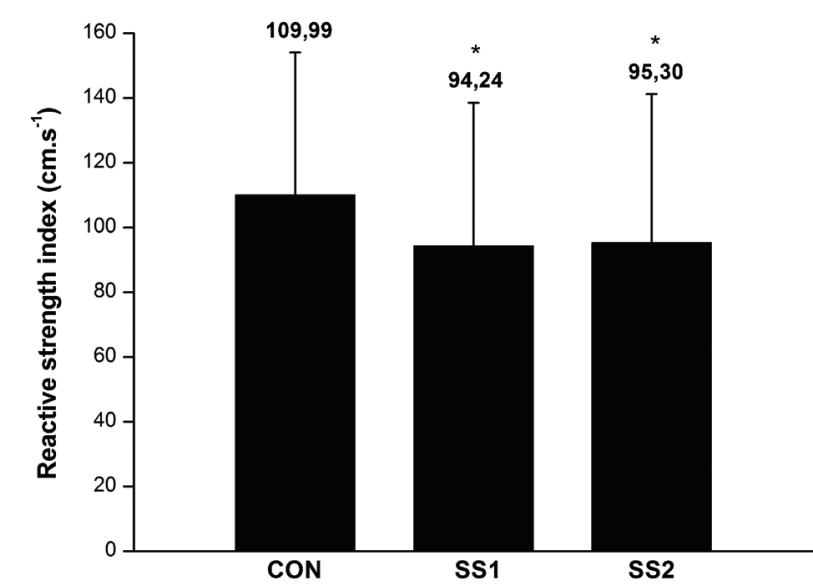

Figure 2. Means and standard deviations for jump height (a), contact time (b) and reactive strength index (c) for control (CON), drop jump at optimal drop height preceded by an SS exercise session (SS1) and drop height $20 \mathrm{~cm}$ below the optimal drop height preceded by an SS exercise session (SS2). * Significant different from CON $(p<0.05)$.

Most studies have suggested a strength deficit induced by previous stretching exercises. For example, Bradley et al. (2007) observed an acute reduction of $4 \%$ in vertical jump height after $\mathrm{SS}$ in male college students. Additionally, Power, Behm, Cahill, Carroll, and Young (2004) showed increase in contact time after 
Table 1. Effect size values for jump height, contact time and reactive strength index between the three experimental conditions.

\begin{tabular}{llll}
\hline & CON vs. SS1 & CON vs. SS2 & SS1 vs. SS2 \\
\hline Jump height & 0.601 & 0.723 & 0.108 \\
Contact time & 0.335 & 0.241 & 0.101 \\
Reactive & 0.376 & 0.345 & 0.025 \\
strength index & & & \\
\hline
\end{tabular}

CON: jump without previous static stretching; SS1: drop jump at optimal drop height preceded by an SS exercise session; SS2: drop height $20 \mathrm{~cm}$ below the optimal drop height preceded by an SS exercise session.

SS and subsequent decreases over $2 h$ poststretching period. Our results are in agreement with the literature because we have noted a decrease in jump height and an increase in contact time after SS. These findings could be explained by deleterious effects caused by SS on the utilization of the elastic energy stored in the stretch-shortening cycle (Hough; Ross \& Howatson, 2009; Power et al., 2004) and an alteration in the sensitivity of the shortening reflex (Rosenbaum \& Hennig, 1995).

The reactive strength index was reduced when SS was performed prior to drop jump and remained reduced when the drop height was decreased. Likewise, the jump height was greater in the CON than in the two stretching conditions. Nevertheless, the contact time was the only parameter that was significantly influenced by a reduction in the drop height. The contact time was reduced by SS but returned to $\mathrm{CON}$ values after a reduction in drop height. This suggests that a change in the initial height and consequently the impact load mainly affects the braking phase and the time spent in strength production but has no effect on the push-off phase, i.e., jump height. Thus, when the drop height is kept equal for CON after a SS protocol, the initial braking phase requires an increased time for deceleration.

The reduction in the contact time after SS2 suggests that the $\mathrm{ODH}$ should be reduced when SS is performed prior to jumps, especially when the contact time is the main performance-related parameter. This could be explained by the fact that during the fall the body is exposed to gravitational acceleration. Thus, in greater drop heights the individual lands at a greater velocity, requiring more eccentric force production to break the movement (Gollhofer \& Kyrolainen, 1991). Based on our results, in conditions where the muscles are previously stretched, it seems that a decrease in drop height enabled a more efficient eccentric contraction, which demanded less time to alter the movement direction and a minor contact time. It is possible that the contact time was restored with the reduction in drop height during SS2 because it may have reduced any negative effects from the stretch-induced force deficit, such as the ability of the muscle-tendon unit to store elastic energy (Cramer et al., 2004). Additionally, because the activation of the plantar flexor muscles is diminished by both SS (Fowles, Sale, \& Macdougall, 2000) and excessive drop heights (Leukel, Taube, Gruber, Hodapp, \& Gollhofer, 2008), probably to prevent tendomuscular injuries (Gollhofer et al., 1991; Leukel et al., 2008), the reduction in drop height could result in a lower inhibition of muscle activation, which results in faster power production and a lower contact time.

\section{Conclusion}

In conclusion, $\mathrm{SS}$ seems to interfere negatively with drop jump performance by reducing the jump height and increasing the contact time. A reduction in drop height after SS modifies the contact time but not the jump height and reactive strength index. Our results suggest that when SS is used in training routines involving drop jump, the drop height should be decreased to maintain an ideal contact time. From a practical view point, during training sessions in which drop jump is being performed, the warm-up routines should be prescribed without SS exercises. Additionally, if the enhancement in contact time is the main objective of a particular session and the warm-up routine is composed of SS exercises, the optimal drop height should be altered to a lower height.

\section{References}

Ball, N.B., Stock, C.B., \& Scurr, J.C. (2010). Bilateral contact ground reaction forces and contact times during plyometric drop jumping. Journal of Strength and Conditioning Research, 24(10): 2762-2769.

Baltaci, G., Um, N., Tunay, V., Besler, A., \& Gerçeker, S. (2003). Comparison of three different sit and reach tests for measurement of hamstring flexibility in female university students. British Journal of Sports Medicine, 37,59-61.

Behm, D.G. \& Kibele, A. (2007). Effects of differing intensities of static stretching on jump performance. European Journal of Applied Physiology, 101, 587-94.

Borg, G. (1998). Borg's Perceived Exertion and Pain Scales. Champaign, IL: Human Kinetics.

Bradley, P.S., Olsen, P.D., \& Portas, M.D. (2007). The effect of static, ballistic, and proprioceptive neuromuscular facilitation stretching on vertical jump performance. Journal of Strength and Conditioning Research, 21(1): 223-226.

Byrne, P.J., Moran, K., Rankin, P., \& Kinsella, S. (2010). A comparison of methods used to identify 'optimal' drop height for early phase adaptations in depth jump training. Journal of Strength and Conditioning Research, 24(8): 2050-2055.

Cramer, J.T., Housh, T.J., Johnson, G.O., Miller, J.M., Coburn, J.W. \& Beck, T.W. (2004). The acute effects of static stretching on peak torque in women. Journal of Strength and Conditioning Research, $18,176-182$.

Fletcher, I.M. \& Monte-Colombo, M.M. (2010). An investigation into the possible physiological mechanisms associated with changes in performance related to acute responses to different preactivity stretch modalities. Applied Physiology, Nutrition and Metabolism, 35, 27-34.

Fowles, J.R., Sale, D.G., \& Macdougall, J.D. (2000). Reduced strength after passive stretch of the human plantar flexors. Journal of Applied Physiology,89, 1179-1188.

Gollhofer, A. \& Kyrolainen, H. (1991). Neuromuscular control of the human leg extensor muscles in jump exercises under various stretch-load conditions. International Journal of Sports Medicine, 12(1), 34-40.

Hough, P.A., Ross, E.Z., \& Howatson, G. (2009). Effects of dynamic and static stretching on vertical jump performance and electromyographic activity. Journal of Strength and Conditioning Research, 23(2), 507-512.

Kyröläinen, H., Avela, J., Mcbride, J.M., Koskinen, S., Andersen, J L., Sipilä, S., ..., Komi, P.V. (2004). Effects of power training on mechanical efficiency in jumping. European Journal of Applied Physiology, 91, 155-59. 
Laffaye, G., Bardy, B., \& Taiar, R. (2006). Upper-limb motion and drop jump: effect of expertise. Journal of Sports Medicine and Physical Fitness, 46, 238-47.

Leukel, C., Taube, W., Gruber, M., Hodapp, M., \& Gollhofer, A. (2008). Influence of falling height on the excitability of the soleus H-reflex during drop jumps. Acta Physiologica, 192, 569-76.

Malisoux, L., Francaux, M., Nielens, H., \& Theisen, D. (2006). Stretch-shortening cycle exercises: an effective training paradigm to enhance power output of human single muscle fibers. Journal of Applied Physiology, 100, 771-779.

Markovic, G. (2007). Does plyometric training improve vertical jump height? A meta-analytical review. British Journal of Sports Medicine, 41, 349-355.

Miller, M.G., Herniman, J.J., Ricard, M.D., Cheatham, C.C. \& Michael, T.J. (2006). The effects of a 6-week plyometric training program on agility. Journal of Sports Science and Medicine, 5, 459-465.

Power, K., Behm, D., Cahill, F., Carroll, M., \& Young, W. (2004). An acute bout of static stretching: effects on force and jumping performance. Medicine Science in Sports and Exercise, 4, 1389-1396.

Rhea, M. (2004). Determining the magnitude of treatment effects in strength training research through the use of the effect size. Journal of Strength and Conditioning Research, 18(4), 918-920.

Rosenbaum, D., \& Hennig, E.M. (1995). The influence of stretching and warm-up exercises on Achilles tendon reflex activity. Journal of Sports Sciences, 13, 481-490.

Samogin Lopes, F.A., Menegon, E.M., Franchini, E., Tricoli, V. \& Bertuzzi, R.C. (2010). Is acute static stretching able to reduce the time to exhaustion at power output corresponding to maximal oxygen uptake? Journal of Strength and Conditioning Research, 24(6), 1650-1656.

Spurrs, R.W., Murphy, A.J., \& Watsford, M.L. (2003). The effect of plyometric training on distance running performance. European Journal of Applied Physiology, 89(1), 1-7.

Thomas, K., French, D., \& Hayes, P.R. (2009). The effect of two plyometric training techniques on muscular power and agility in youth soccer players. Journal of Strength and Conditioning Research, 23(1), 332-335.

Vissing, K., Brink, M., Lønbro, S., Sørensen, H., Overgaard, K., Danborg, K., ..., Aagaard, P. (2008). Muscle adaptations to plyometric vs. resistance training in untrained young men. Journal of Strength and Conditioning Research, 22(6), 1799-1810.

Young, W.B. \& Elliot, S. (2001). Acute effects of static stretching, proprioceptive neuromuscular facilitation stretching and maximum voluntary contractions on explosive force production and jumping performance. Research Quarterly for Exercise and Sport, 72(3), 273-279.

Zatsiorsky, V.M. \& Kraemer, W.J. (2007). Science and Practice of Strength Training. Champaign, IL: Human Kinetics.

\section{Authors' note}

Leonardo A. Pasqua, Nilo M. Okuno, Mayara V. Damasceno and Rômulo Bertuzzi are members of the Endurance Performance Research Group. School of Physical Education and Sport, University of São Paulo (USP), São Paulo, Brazil.

Adriano. E. Lima-Silva is member of the Sports Science Research Group. Faculty of Nutrition, Federal University of Alagoas (UFAL), Maceió, Brazil.
Leonardo A. Pasqua (FAPESP: 2010/13913-6) and Mayara V. Damasceno (FAPESP: 2011/02769-4) are supported with scholarships (master's level) from Fundação de Amparo à Pesquisa do Estado de São Paulo.

\section{Corresponding author:}

Leonardo A. Pasqua

Department of Sport, School of Physical Education and Sport, University of São Paulo (USP), São Paulo, Brazil

Prof. Melo de Morais Avenue 65, Cidade Universitária, São Paulo, 05371-140, SP.

Email: leonardo.pasqua@usp.br

Manuscript received on January 22, 2013

Manuscript accepted on November 24, 2013

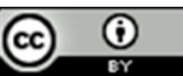

